\title{
Aprender a mirar
}

\section{Learn to look}

\section{Marta Lage de la Rosa}

Universidad Complutense de Madrid (España)

malage@ucm.es
Recibido: 13/09/2020 Revisado: 18/10/2020

Aceptado: 23/11/2020 Publicado: 14/12/2020

\section{Resumen:}

Es un fotoensayo de creación colaborativa de una experiencia artístico pedagógica en el período de confinamiento.

Los objetivos coinciden con los generales de la Educación Infantil y contribuyen a desarrollar importantes capacidades en la formación de profesorado.

El proyecto creativo y artístico permite conectar con la espiritualidad, esencia del ser humano. Es un acercamiento a la belleza de lo imperfecto, lo incompleto, lo cambiante, pone de manifiesto el valor de aquello modesto y humilde tan importante en educación.

El resultado responde a las preguntas de partida: ¿Se puede enseñar a mirar?, ¿Cómo se aprende a mirar?, ¿En otras culturas se mira de la misma forma?, ¿Cómo se mira en la infancia?, ¿Qué y cómo se aprende? En la experiencia destaca el aprendizaje activo, el valor del error, de la sensibilidad, la belleza, la aceptación de lo imperfecto, el camino como meta en la construcción del aprendizaje y de la vida para la felicidad. Sólo se enseña lo que se es. Sólo se aprende lo que se vive.

\section{Sugerencias para citar este artículo,}

Lage de la Rosa, Marta, (2020). Aprender a mirar. Tercio Creciente (Monográfico extraordinario IV), (pp. 7-32), https://dx.doi.org/10.17561/rtc.extra4.5745

LAGE DE LA ROSA, MARTA. Aprender a mirar. Tercio Creciente (Monográfico extraordinario IV), diciembre 2020, pp. 7-32, https://dx.doi.org/10.17561/rtc.extra4.5745 


\section{Abstract:}

It is a collaborative photo-essay of a pedagogical artistic experience in the period of Covid 19 Spain confinement.

The objectives coincide with the general ones of Spanish Early Childhood Education Law and contribute to developing important skills in the teachers training.

The creative and artistic project allows connecting with spirituality like the essence of the human being. It is an approach to the imperfect beauty, the incomplete, the changing, it reveals the value of what is modest and humble so important in education.

The result responds to the starting questions: Can you teach to look? How do you learn to look? In other cultures, do you look the same way? How do you look at it in childhood? What and how do you learn? The experience highlights active learning, the value of error, sensitivity, beauty, acceptance of the imperfect, the path as a goal in the construction of learning and life for happiness. You only teach what you are. You only learn what you live.

Palabras Clave: Aprendizaje activo, Aprendizaje visual, Fotografía, Lenguaje visual, Formación docente.

Keywords: Active learning, Visual learning, Photography, Visual language, Teacher training.

\section{Sugerencias para citar este artículo,}

Lage de la Rosa, Marta, (2020). Aprender a mirar. Tercio Creciente (Monográfico extraordinario IV), (pp. 7-32), https://dx.doi.org/10.17561/rtc.extra4.5745

LAGE DE LA ROSA, MARTA. Aprender a mirar. Tercio Creciente (Monográfico extraordinario IV), diciembre 2020, pp. 7-32, https://dx.doi.org/10.17561/rtc.extra4.5745 


\section{Introducción}

Este artículo es un fotoensayo de creación colaborativa de una experiencia artístico pedagógica en el período de confinamiento.

Se produce una investigación artística que ofrece como resultados de dicha investigación, las composiciones que conjuntamente se reúnen en este fotoensayo. Dicho conjunto responde a las preguntas de partida que cada receptor/a deberá interpretar y que son los objetivos.

Los objetivos coinciden con los generales de la Educación Infantil y contribuyen a desarrollar importantes capacidades en la formación de profesorado.

El proyecto creativo y artístico permite conectar con la espiritualidad, esencia del ser humano. Es un acercamiento a la belleza de lo imperfecto, lo incompleto, lo cambiante, pone de manifiesto el valor de aquello modesto y humilde tan importante en educación.

El resultado responde a las preguntas de partida: ¿Se puede enseñar a mirar?, ¿Cómo se aprende a mirar?, ¿En otras culturas se mira de la misma forma?, ¿Cómo se mira en la infancia?, ¿Qué y cómo se aprende? En la experiencia destaca el aprendizaje activo, el valor del error, de la sensibilidad, la belleza, la aceptación de lo imperfecto, el camino como meta en la construcción del aprendizaje y de la vida para la felicidad. Sólo se enseña lo que se es. Sólo se aprende lo que se vive.

En las siguientes páginas se ofrece la aportación de cada participante. 
Revista de Estudios en Sociedad, Artes y Gestión Cultural ISSN: 2340-9096
Monográfico Extraordinario IV

Lugares y No Lugares para la creación

Lugares y No Lugares para la creación
Diciembre 2020

DOI: https://dx.doi.org/10.17561/rtc.extra4.5745 Investigación

El ensayo

\section{LA BELLEZA QUE TIENE HISTORIAS POR NOÉMI TOHT}

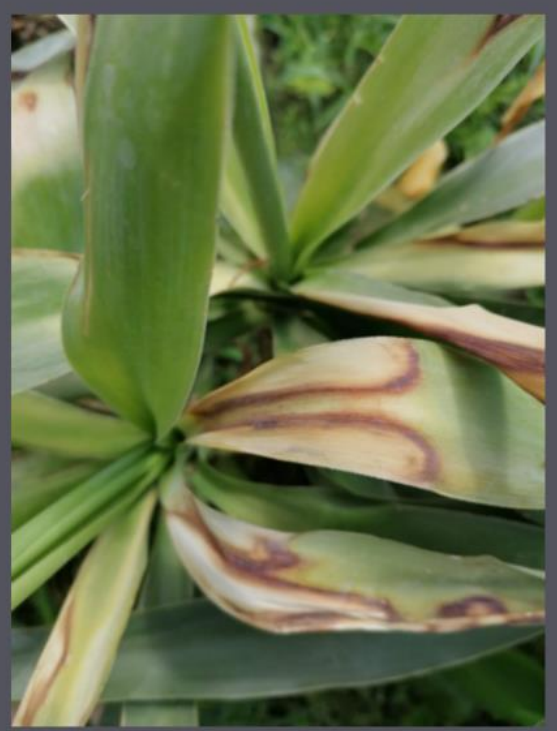

Las flores silvestres son lo primero que me vino a la mente cuando he leído sobre el wabi-sabi.

Son humildes y preciosas con su simplicidad.

El Diente de León tiene dos formas, primero son flores amarillas y después blancas, simbolizando su edad. Sus molinillos blancos que se elevan con el viento deslumbran a todos con su belleza natural y pura. Autora: Noémi Thot, 2020.
Esta planta de mi jardín está quemada por el sol que deja manchas en sus hojas. Me parecen bellas estas marcas, cuentan su historia y muestra su vulnerabilidad. La vulnerabilidad la hace única y más fuerte. Autora: Noèmi Thot, 2020.

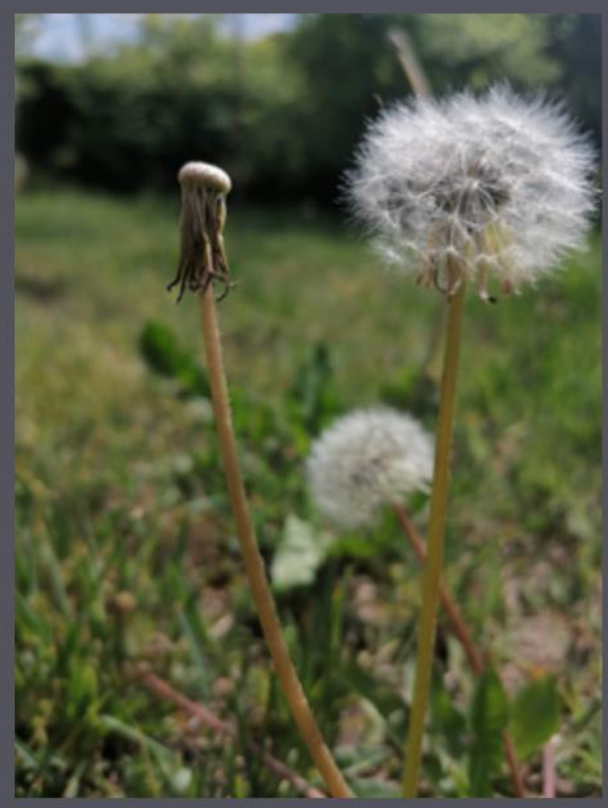


Revista de Estudios en Sociedad, Artes y Gestión Cultural ISSN: 2340-9096
Monográfico Extraordinario IV

DOI: https://dx.doi.org/10.17561/rtc.extra4.5745 Investigación

Lugares y No Lugares para la creación Diciembre 2020

\section{LA BELLEZA QUE TIENE HISTORIAS POR NOÉMI TOHT}

Recibí estas tazas como regalo de mi madre. Fueron hechas a mano.

No son perfectamente iguales. Las asas son distintas. La decoración es de puntos distintos pintados a mano. Están un poco desgastadas pero son hermosas para mi. Llevan el trabajo de su creador/a y los momentos que experimenté mientras tomaba café. El entorno también tiene desperfectos porque vivo en una casa antigua. Sin embargo, para mí, es hermosa, ordenada, hogareña, llena de recuerdos. Autora: Noémi Thot, 2020.

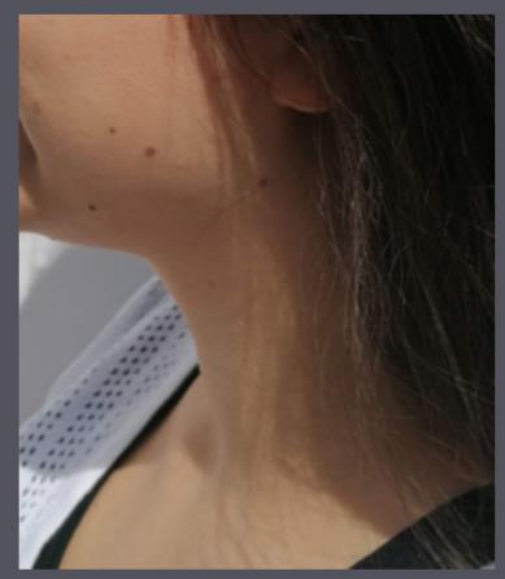

La piel blanca y clara es la belleza de nuestra sociedad. Desde mi infancia fui quien tiene la piel más oscura, además tengo muchos lunares en mi piel, incluso en mi cara que no puedo cubrir con prendas. Durante mi adolescencia cuando tuve crisis de identidad asomaron pensamientos como "Soy extraña, ¿por qué mi piel no es clara?". Cuando mi querido sobrino era pequeño, los descubrió al examinar mi cara. Luego señaló con el dedo mis lunares y sonrió. Nunca olvidaré este momento, él estaba interesado por ellos y le gustaban.

Es un camino largo y dificil el que todos tenemos: aceptarnos a nosotros mismos como somos. Somos diferentes y somos bellas a nuestra manera con desperfectos diferentes que nos hacen personas únicas. Autora: Noémi Thot, 2020

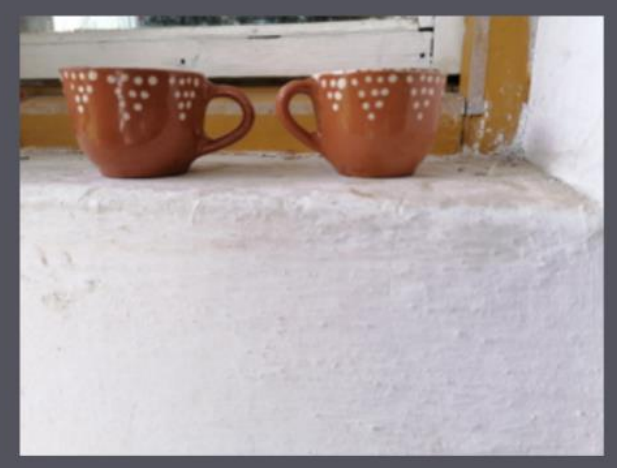

Mi gato lo trajo una señora anciana que acogía a todos los gatitos callejeros hasta que ya no pudo mantenerlos. Mi gato me recuerda a la señora que ya no está viva pero su recuerdo sí está vivo, fue muy amable y alegre y transmitió esto a todo, incluido a sus gatos. En el pelaje de gatito se pueden encontrar diferentes colores. Para mí su rostro es muy especial. A medida que los colores y patrones se mezclan en él. Su personalidad también refleja esto, para mí es diferente de otros gatos.

Mucha gente piensa que solamente los animales de una raza pueden ser bonitos que las mezclas tienen menos valor. No es así, todos son iguales con mucho valor. Autora: Noémi Thot, 2020

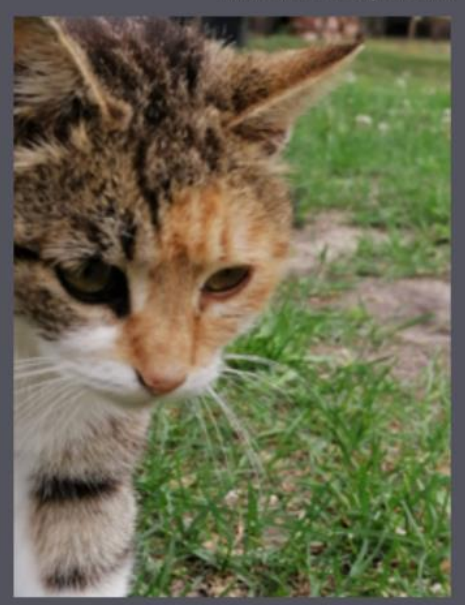


Revista de Estudios en Sociedad, Artes y Gestión Cultural ISSN: 2340-9096
Monográfico Extraordinario IV

DOI: https://dx.doi.org/10.17561/rtc.extra4.5745 Investigación

Lugares y No Lugares para la creación Diciembre 2020

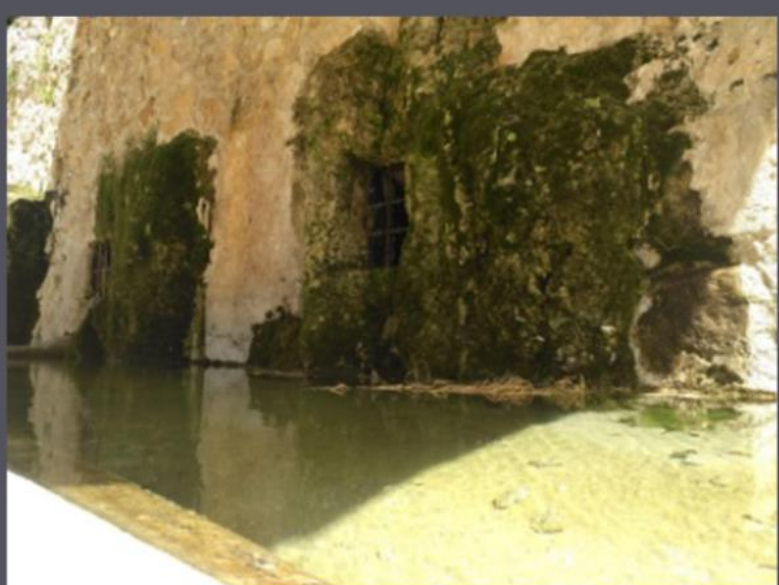

ENCONTRAR LA BELLEZA

EN LO IMPERFECTO POR BIANCA ANDREEA LORDACHE
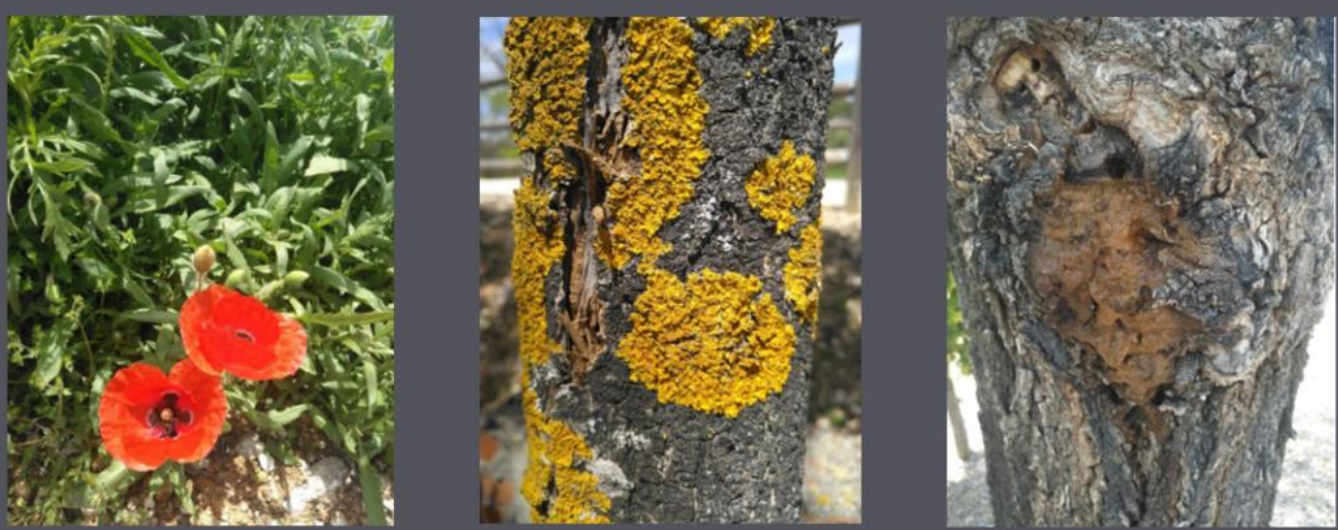

Al empezar a buscar los lugares o cosas "imperfectamente" bellas para fotografiar me he dado cuenta que vivo en un pueblo precioso y que hay lugares imperfectos muy bellos que de normal no me hubiera tomado el tiempo suficiente para observar:

1. Desde lo más sencillo, que puede ser una simple amapola que, las personas de pueblo estamos muy acostumbradas a ver, pero que nunca nos tomamos el tiempo suficiente para observar sus colores o cómo y dónde crecen.

2. El simple tronco roto y lleno de musgo de un árbol, tan imperfecto y precioso a la vez. ¿Cómo se combinan los diferentes colores del tronco seco, del interior y del musgo?, ¿Cómo sobresale la grieta?. 3. Las diferentes caras en el tronco que se han ido formando a lo largo del tiempo y cómo la parte del medio está mojada y caen gotas de agua.

4. El musgo se ha ido extendiendo alrededor de los vanos formando como cortinas exteriores naturales. 
Revista de Estudios en Sociedad, Artes y Gestión Cultural ISSN: 2340-9096
Monográfico Extraordinario IV

DOI: https://dx.doi.org/10.17561/rtc.extra4.5745 Investigación

Lugares y No Lugares para la creación Diciembre 2020

\section{LA BELLEZA DE LA IMPERFECCIÓN POR Andrea Carolina Tituaña}

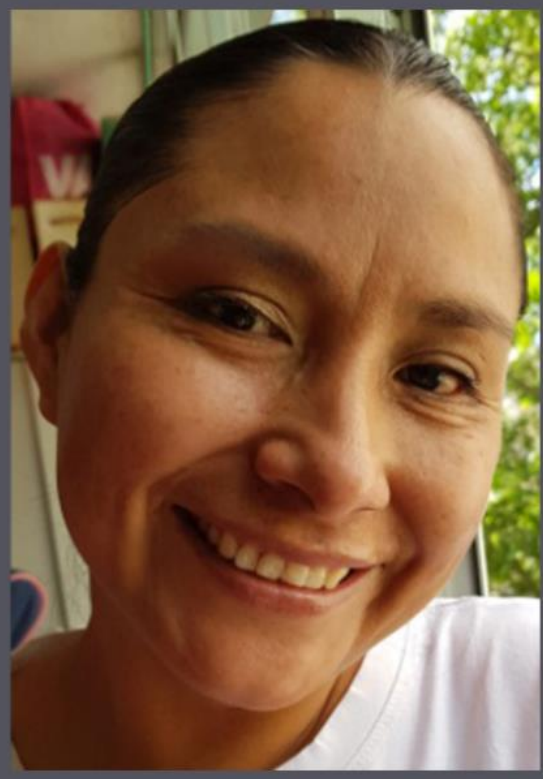

Mirada de madre ¿Qué esconde una mirada? ¿Qué esconden las arrugas y las líneas de expresión de un rostro?

Esta imagen nos muestra la belleza más natural, la belleza madura que ha ido dejando su rastro con el paso del tiempo.

Es una belleza sencilla que va más allá de lo estereotipado. Cada pequeña arruga, cicatriz o mancha son una parte de la esencia de una persona que es bellamente natural, espontánea, frágil pero fuerte, triste pero valiente.

Porque la belleza es vida y la vida es bella como para imponer falsas perfec-

ciones.

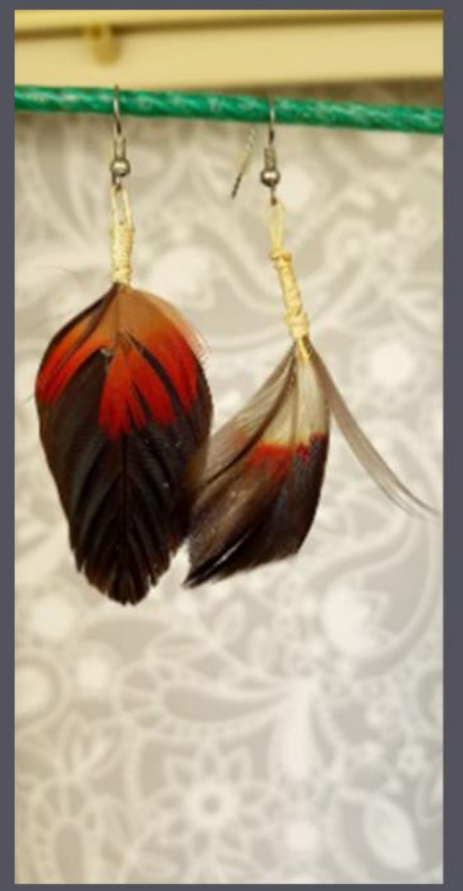

Plumas Amazónicas Muchas de las veces que miro al cielo y veo a un pájaro pasar, atraviesa siempre por mi cabeza la incógnita de qué se sentirá al volar. Luego me imagino que debe ser algo así como una sensación única de libertad y control, de poder sentirte dueño del cielo, de

las nubes, de poder tener ese sentimiento de felicidad y libertad a la vez debe ser una experiencia única. Entonces es ahí, ahí está la belleza, en la libertad pues tal y como dice la canción: "Hay que bonito sería poder volar", y sí, cuánta razón tiene.

Porque la belleza es vida y la vida es bella como para imponer falsas perfecciones. 
Revista de Estudios en Sociedad, Artes y Gestión Cultural ISSN: 2340-9096
Monográfico Extraordinario IV

DOI: https://dx.doi.org/10.17561/rtc.extra4.5745 Investigación

Lugares y No Lugares para la creación Diciembre 2020

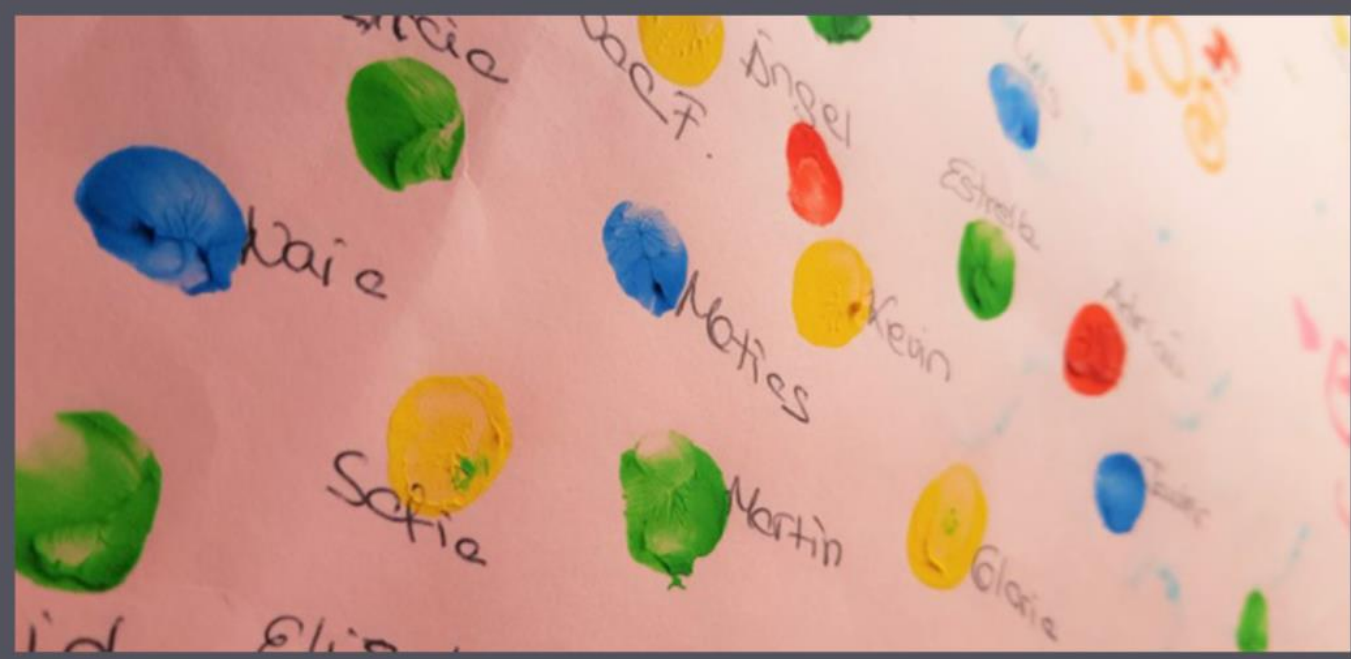

Dejando huella en el camino

No hay nada más bonito, puro e inocente que la huella de un pequeño/a. Una primera marca de su identidad personal.

Son huellas pequeñas, imprecisas, de colores que han sido plasmadas de forma espontánea.

Realmente fue emocionante cuando recibí este regalo como recuerdo de mi estancia en la escuela infantil de prácticas.

Son marquitas pequeñamente imperfectas y hermosas. Hablan por sí solas. 
Revista de Estudios en Sociedad, Artes y Gestión Cultural ISSN: 2340-9096

Lugares y No Lugares para la creación

DOI: https://dx.doi.org/10.17561/rtc.extra4.5745 Investigación

Diciembre 2020

\section{PERCIBIR EL ORDEN CÓSMICO POR DANIEL BERNABÉ GARCÍA}

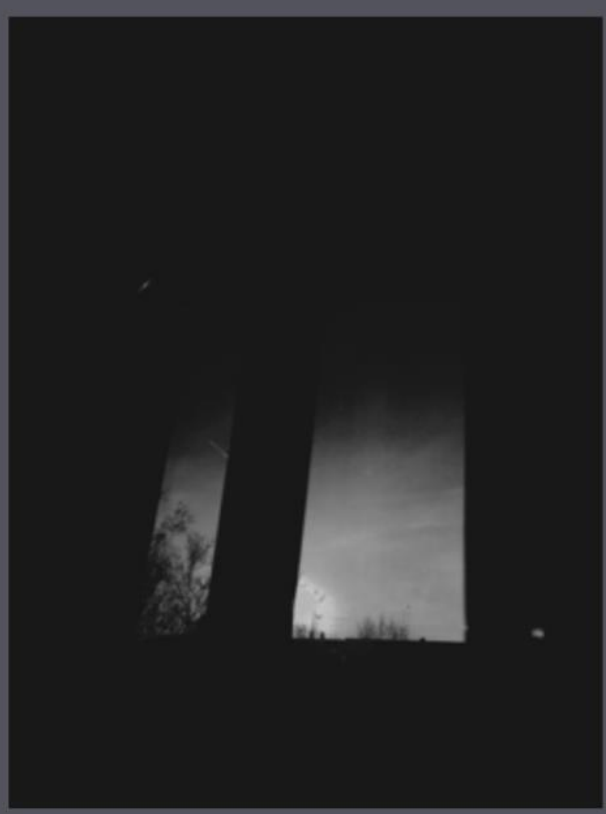

Autor Daniel Bernabé García, 2020

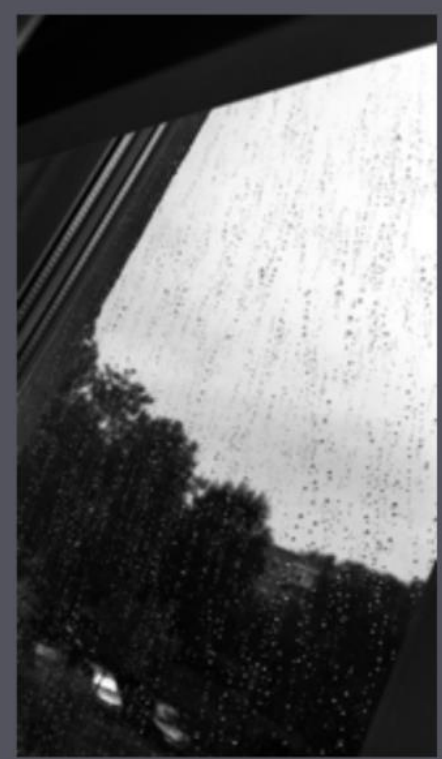

Autor Daniel Bernabé García, 2020

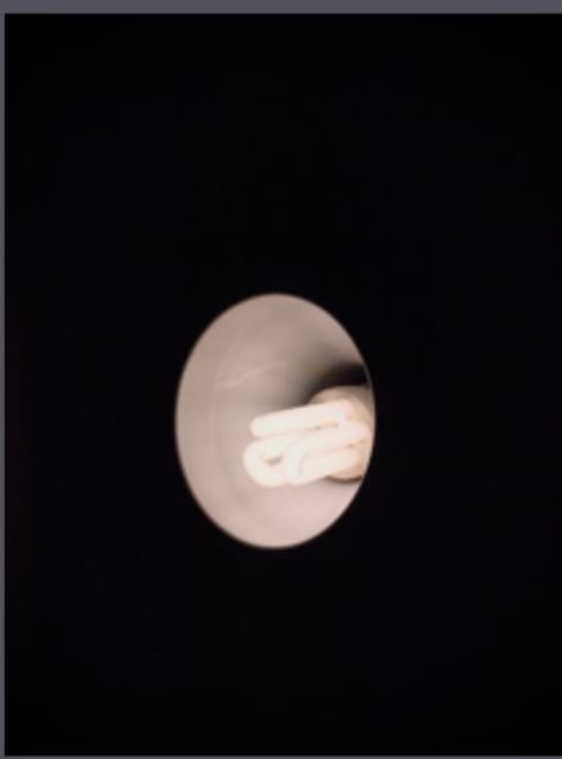

Autor Daniel Bernabé García, 2020 


\section{DEJAR QUE LAS COSAS OCURRAN POR FÁTIMA DOUTROI AMTIOU}

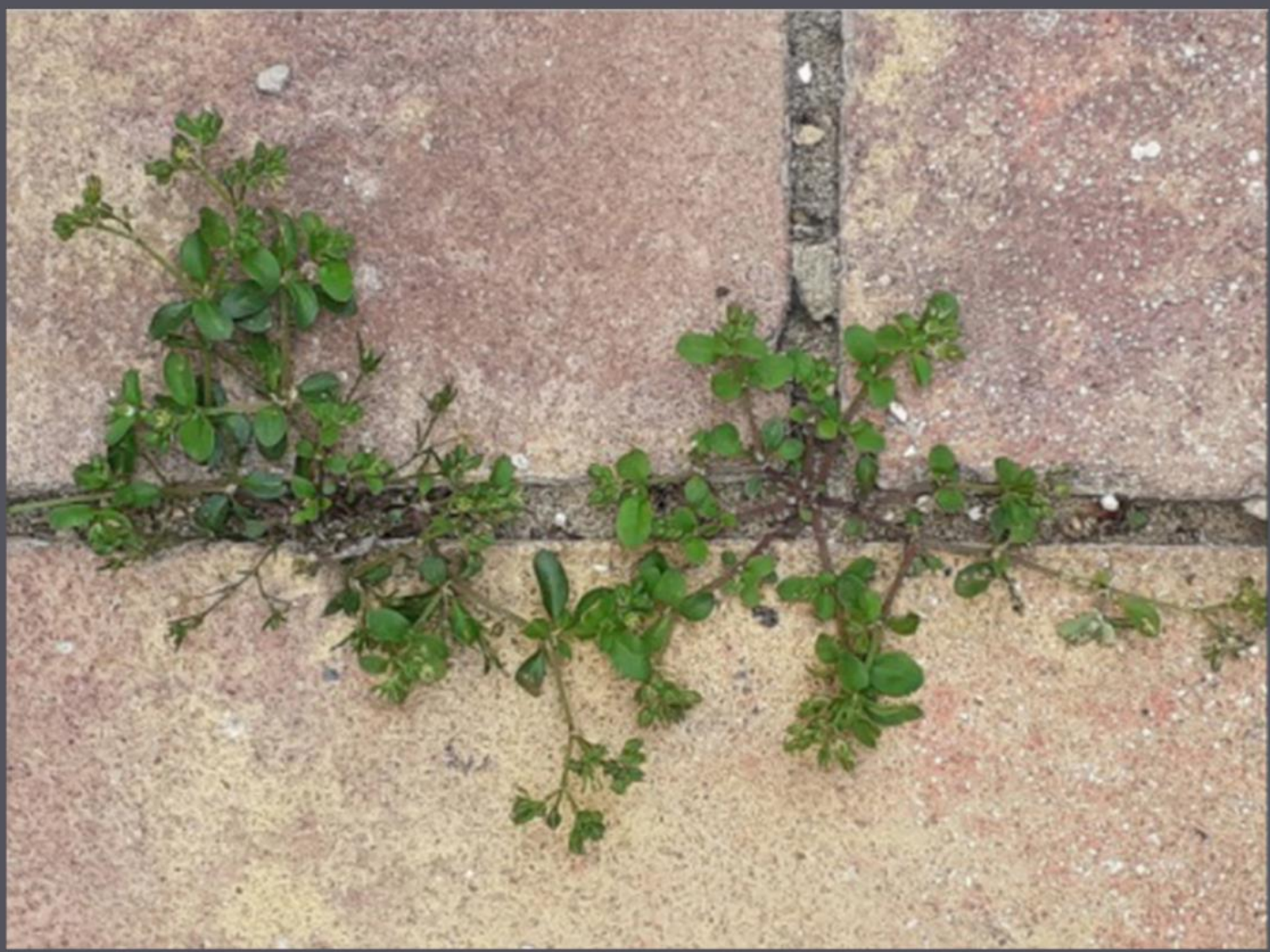




\section{DEJAR QUE LAS COSAS OCURRAN POR KAREN GARCÍA MARTÍNEZ}
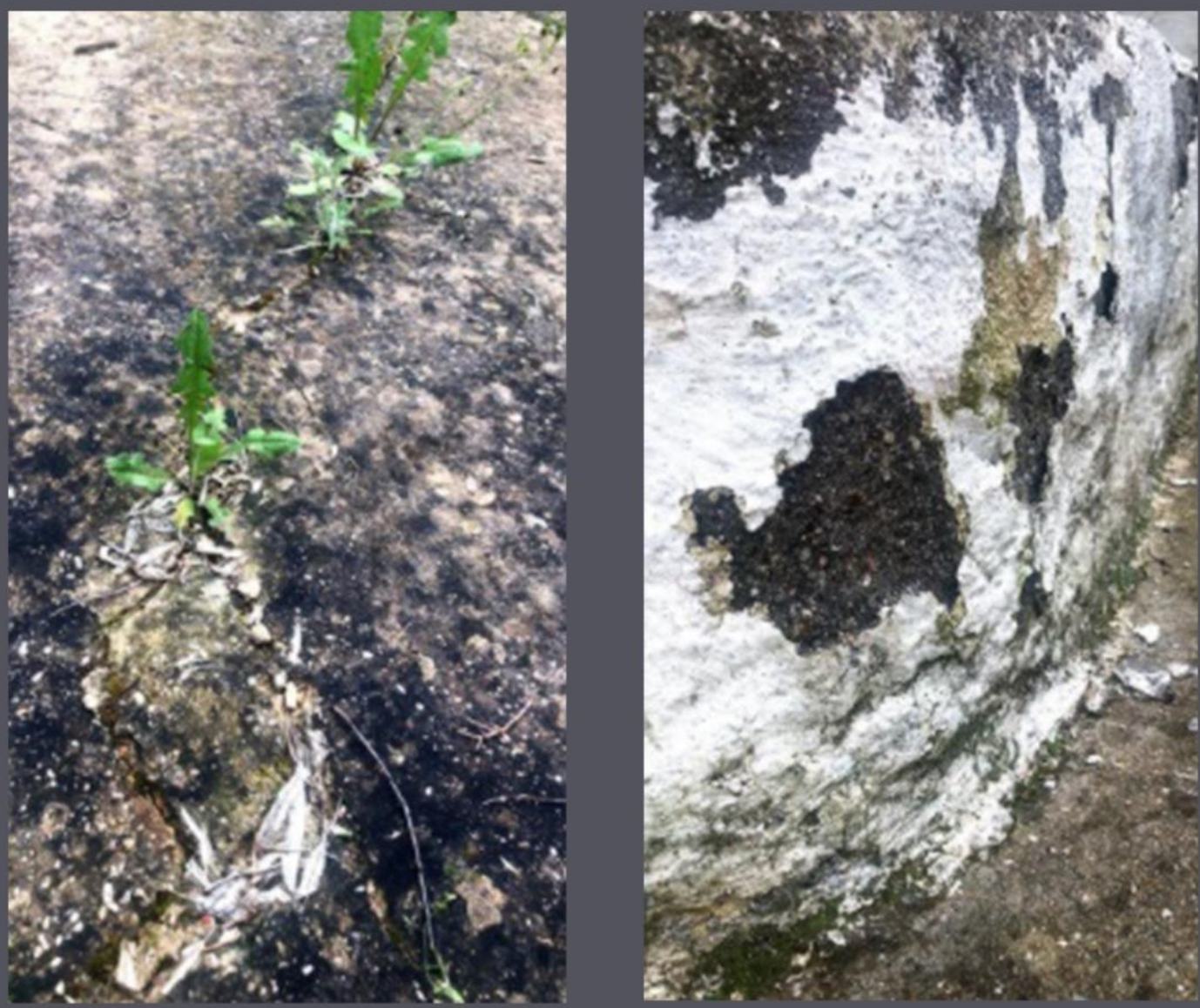
DOI: https://dx.doi.org/10.17561/rtc.extra4.5745

\section{LO INTRASCENDENTE Y LO OCULTO POR LIBIA MARÍA BATISTA}
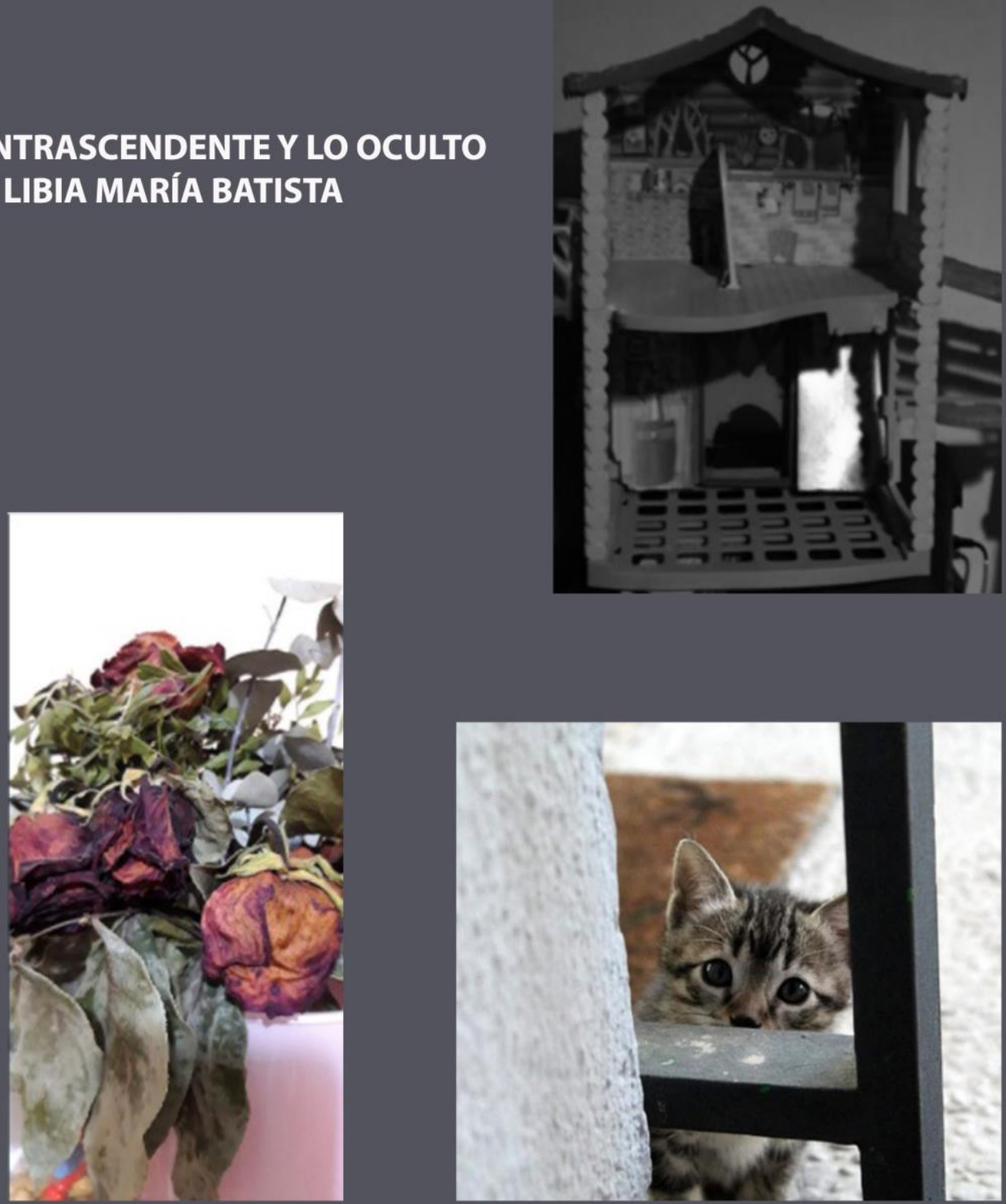


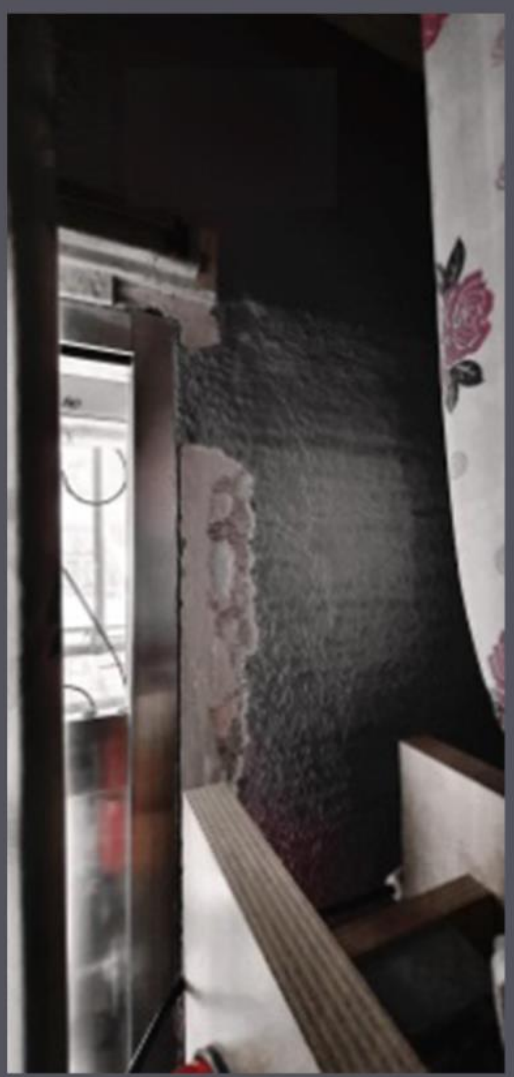

\section{LO PROVISIONAL Y LO EFÍMERO POR LIDIA DIÉGUEZ PARRA}

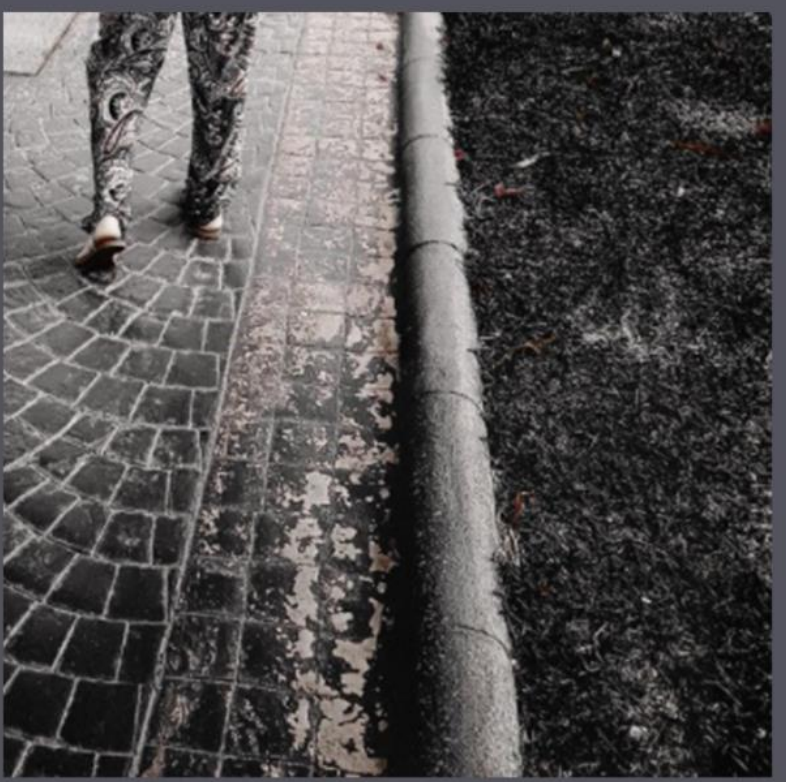




\section{ORIENTADO HACIA DENTRO: ÍNTIMO POR MARÍA CARRASCO PALANCAR}

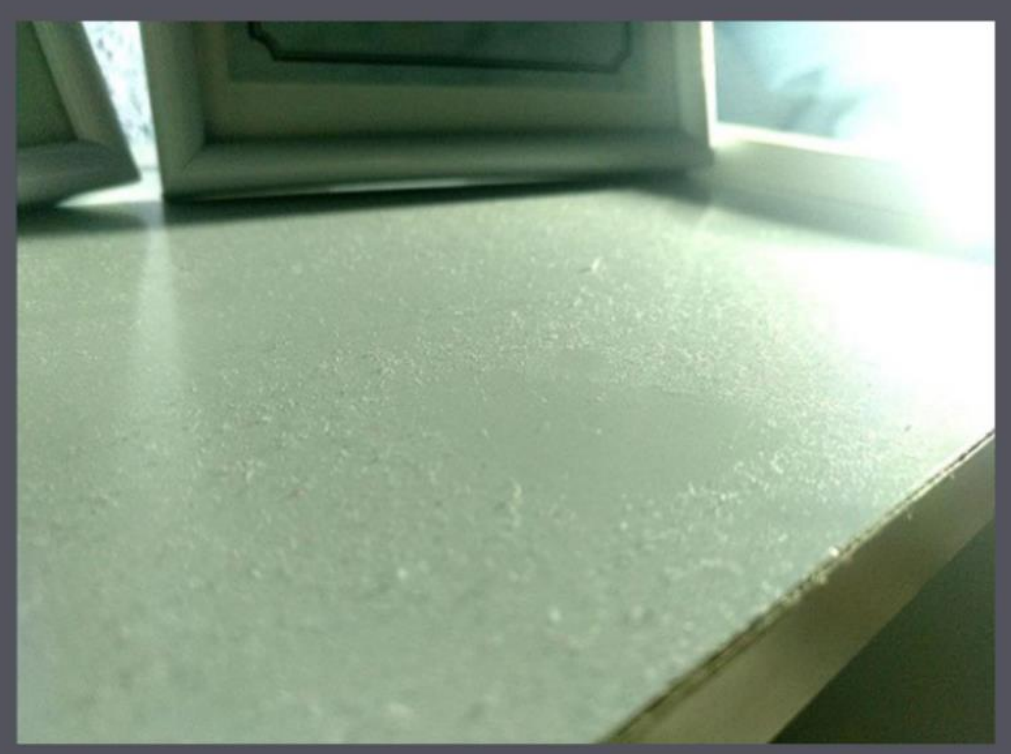

Un hueco entre el polvo
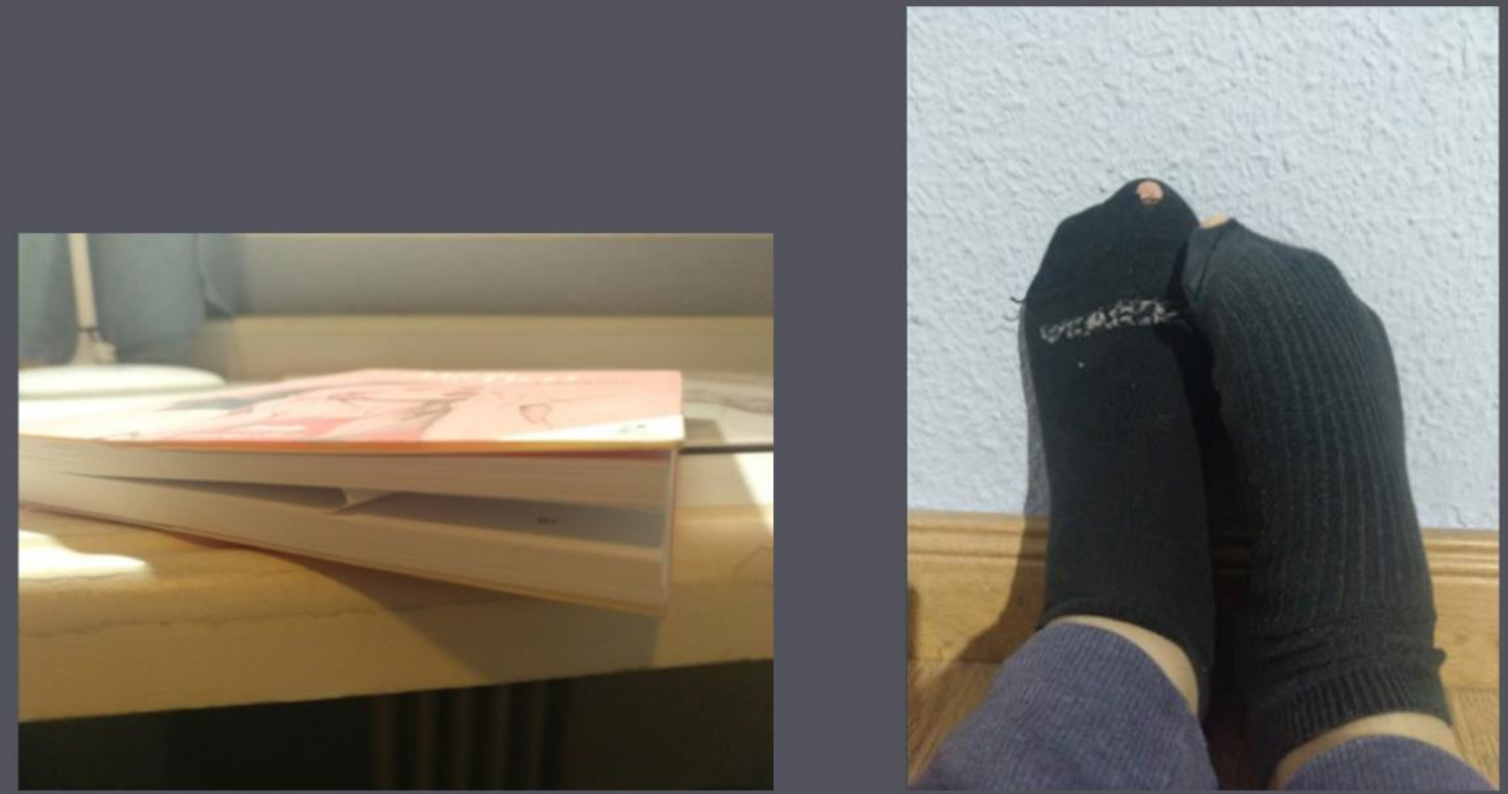
DOI: https://dx.doi.org/10.17561/rtc.extra4.5745

\section{LA BELLEZA Y LA PUREZA POR} MARÍA GALARDO LÓPEZ
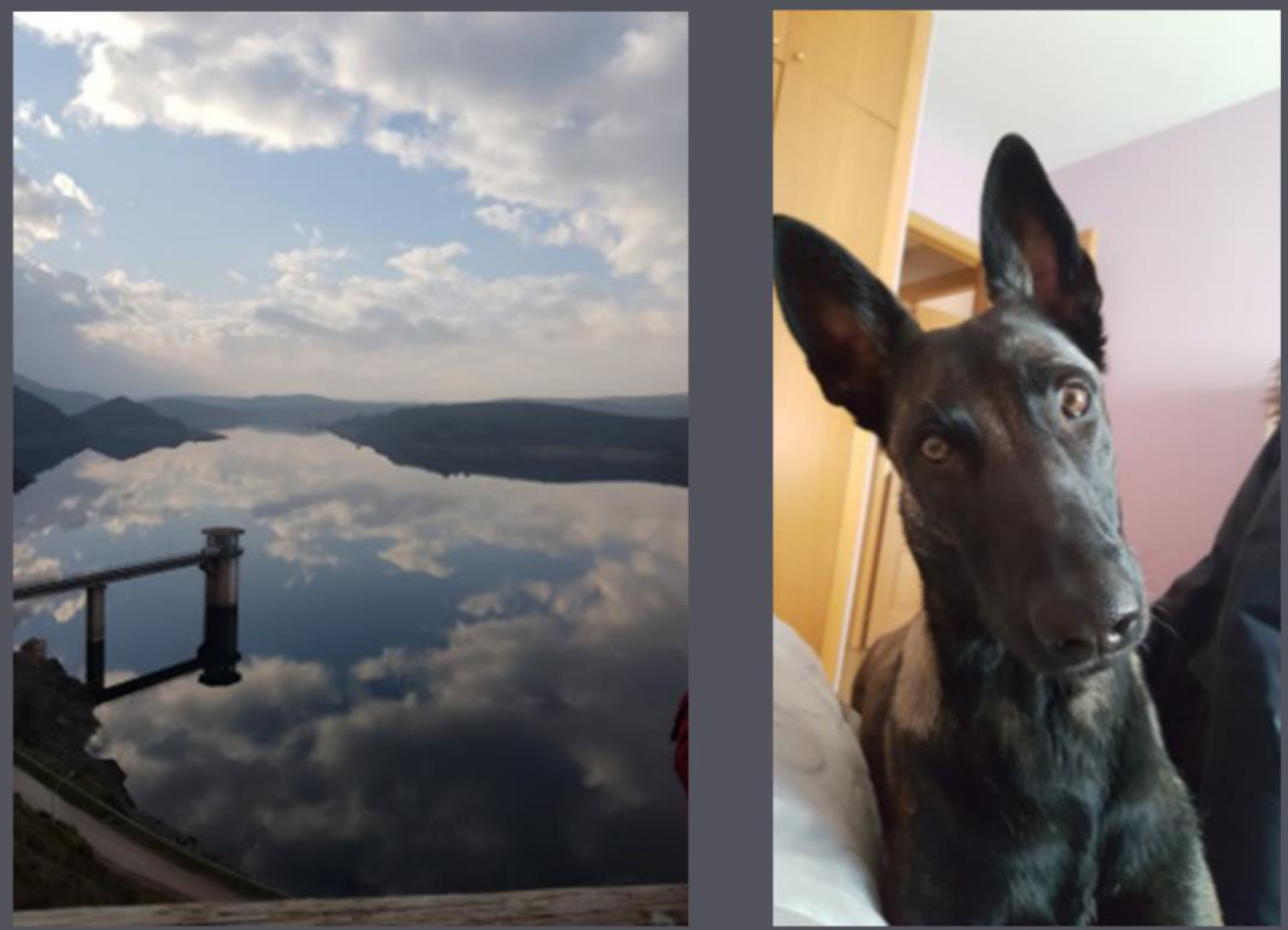


\section{IDEALES DE BELLEZA NO FIGURATIVA} POR MÓNICA GÓMEZ GONZÁLEZ

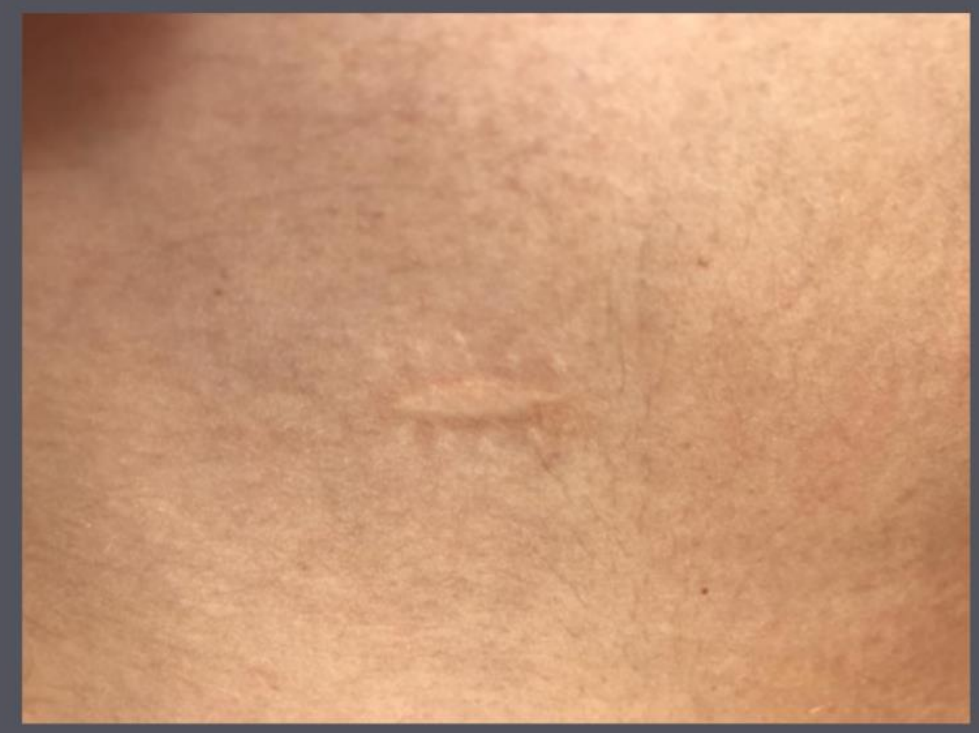


Revista de Estudios en Sociedad, Artes y Gestión Cultural ISSN: 2340-9096
Monográfico Extraordinario IV

DOI: https://dx.doi.org/10.17561/rtc.extra4.5745 Investigación

Lugares y No Lugares para la creación Diciembre 2020

\section{TODA EXISTENCIA COMPARTE EL MISMO DESTINO POR NATALIA BARAKAT ALONSO}
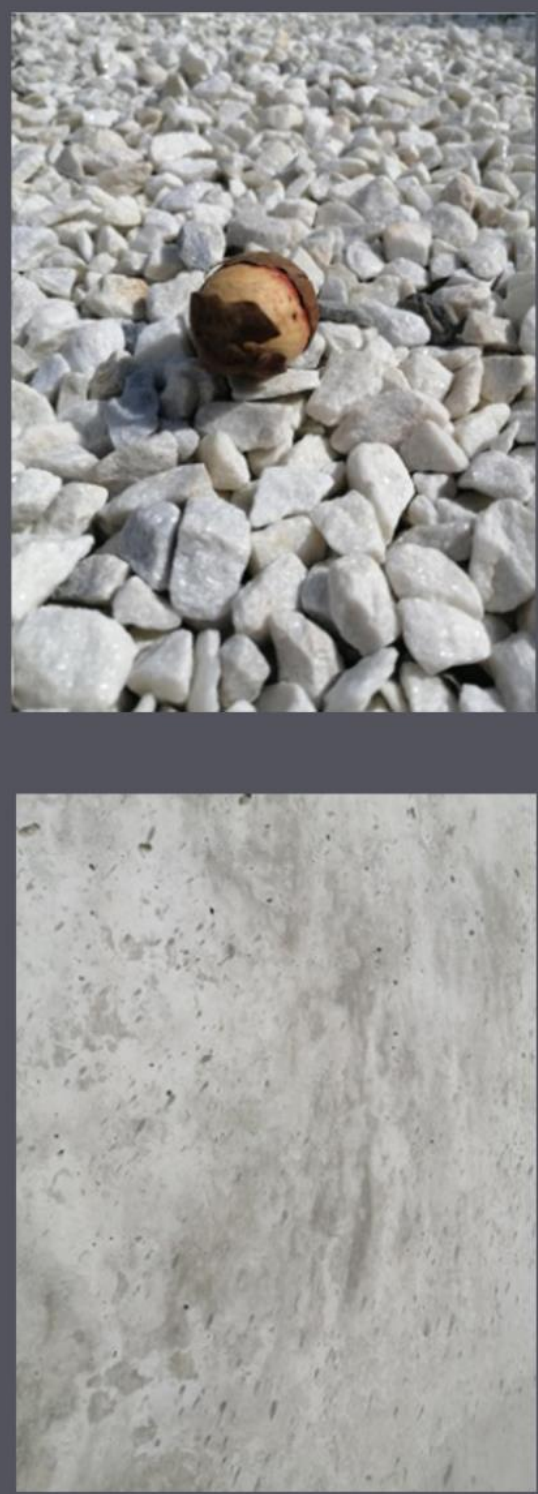

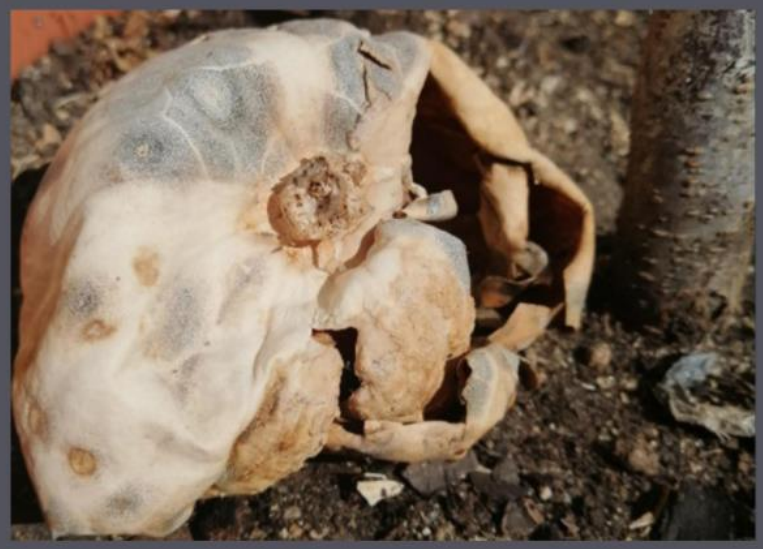

Me he fijado en todos aquellos objetos con defectos tanto artificiales como naturales, todos aquellos cambios que provocan que dejen de tener la apariencia que uno desearía.

Todo aquello que calificaría como imperfecto, para mi supone una nueva versión aún más única y original sin llegar a perder su verdadero valor, como es el caso del hueso de aguacate (imagen 2) que al quitarse su cáscara se puede ver una nueva capa y color que desconocíamos 0 , la pared gris (imagen 3), cuya tonalidad ha ido cambiando a causa de acontecimientos meteorológicos, que han provocado que se formasen orificios y machas, pasando a ser una pared policromática. 
Revista de Estudios en Sociedad, Artes y Gestión Cultural ISSN: 2340-9096
Monográfico Extraordinario IV

\section{PERFECCIÓN EN LO IMPERFECTO POR PAULA CLEMENTE FERNÁNDEZ}

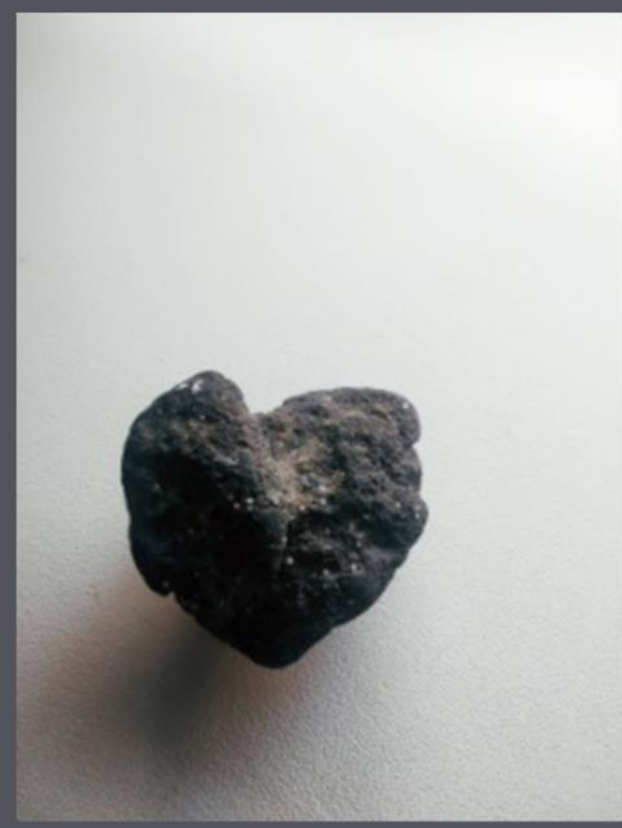

Corazón erosionado

En la piedra se observan pequeñas comisuras provocadas por fenómenos naturales como el choque de las olas, produciendo así la forma y su belleza propia que, representa todo lo que me

aportó un viaje, haciendo que, en cierto modo, en mi corazón se crearan unas "pequeñas comisuras" originadas por la huella que dejaron las personas que me acompañaron, los paisajes y los bonitos recuerdos. Me he fijado en todos aquellos objetos con defectos tanto artificiales como naturales, todos aquellos cambios que provocan que dejen de tener la apariencia que uno desearía.

Siesta

Ese rato en el que una tarde de invierno me hace recuperar vida después de un día eterno, en el que lo primero que pienso al madrugar es en la siesta de esa misma tarde. 0 , también, ese rato una tarde de verano que te hace caer rendida en el sofá y despertarte peor de como te dormiste, además de estar de malhumor por el calor que te ha acompañado durante ese sueño.

Nada más perfectamente imperfecto que aquello $\tan$ cotidiano, $\tan$ asimilado en nuestras rutinas que pasa desapercibido y en lo que hay que indagar para sacar sus matices ocultos.

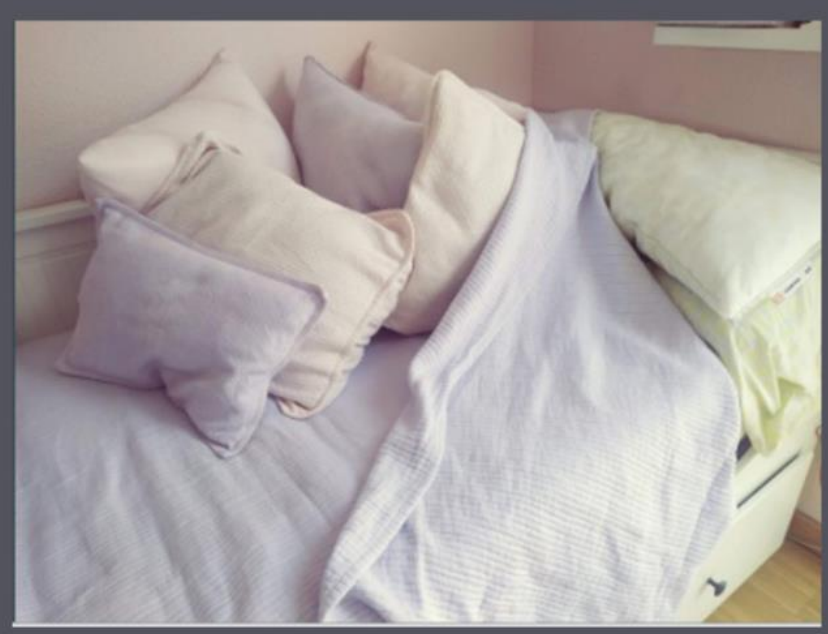




\section{LA GRANDEZA EN LOS DETALLES DESAPERCIBIDOS POR SARA NOVILLO HIDALGO}
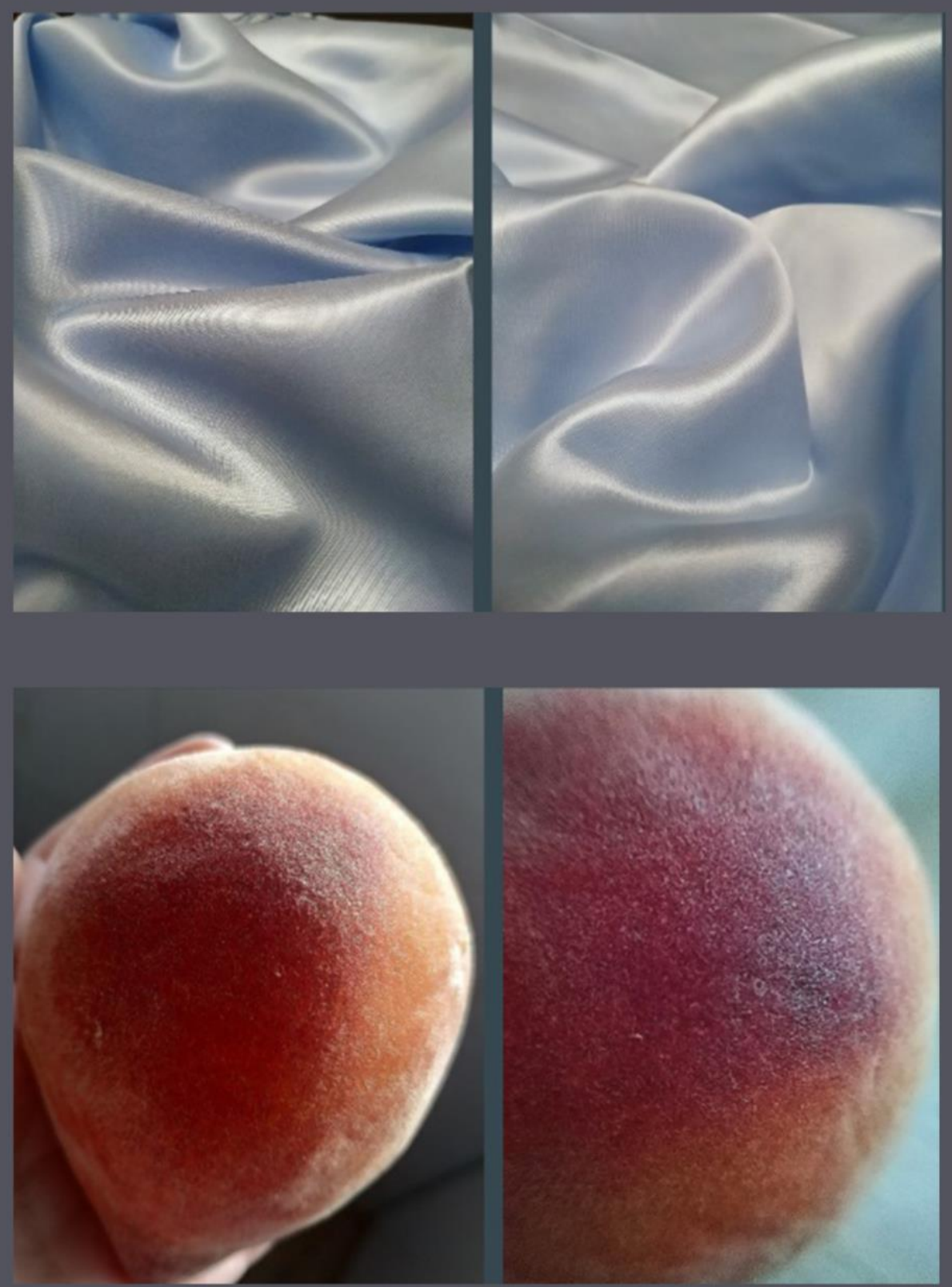
DOI: https://dx.doi.org/10.17561/rtc.extra4.5745 Investigación

Lugares y No Lugares para la creación Diciembre 2020
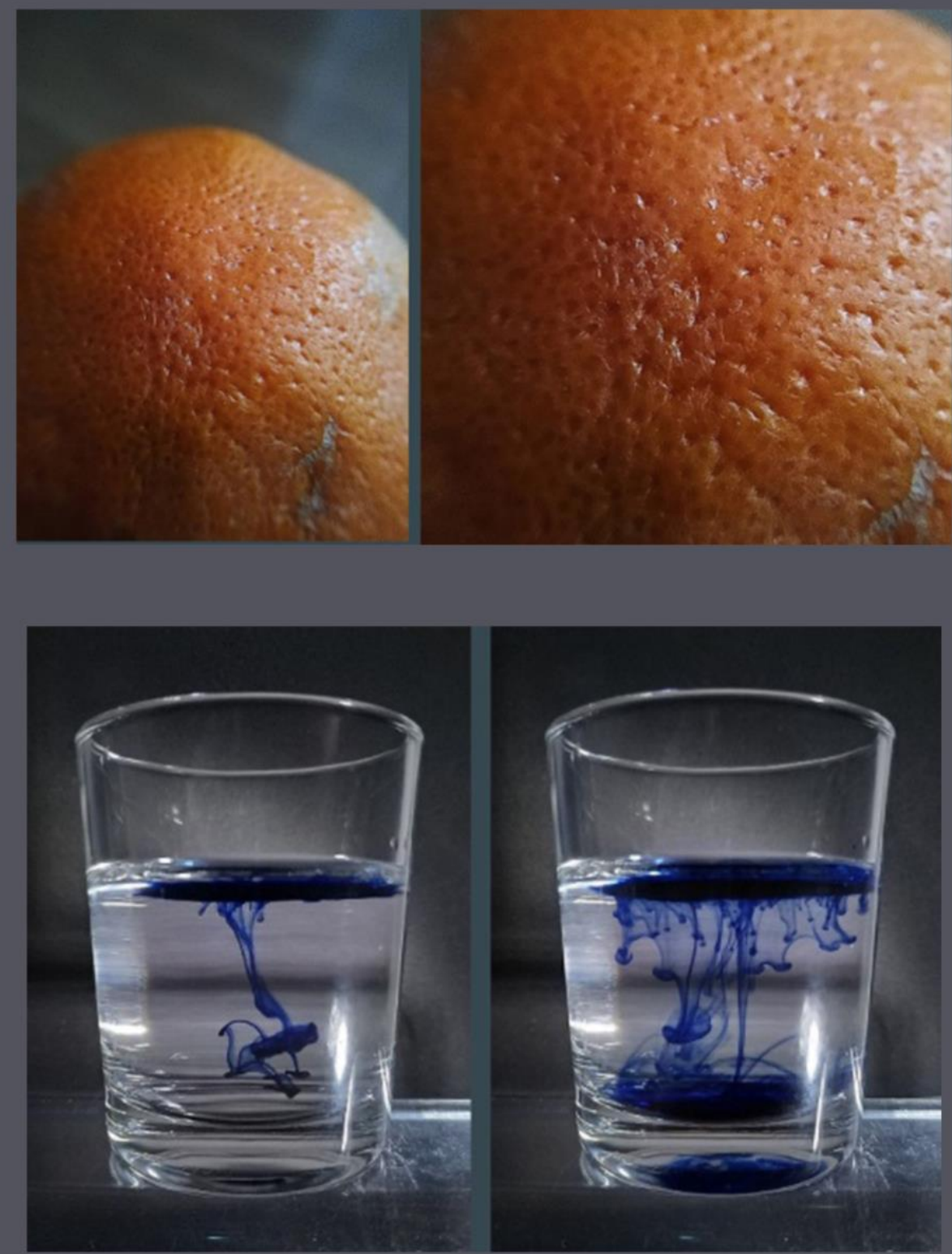


\section{PIEZA ÚNICA Y VARIABLE POR PAULA RUS SIMÓN}
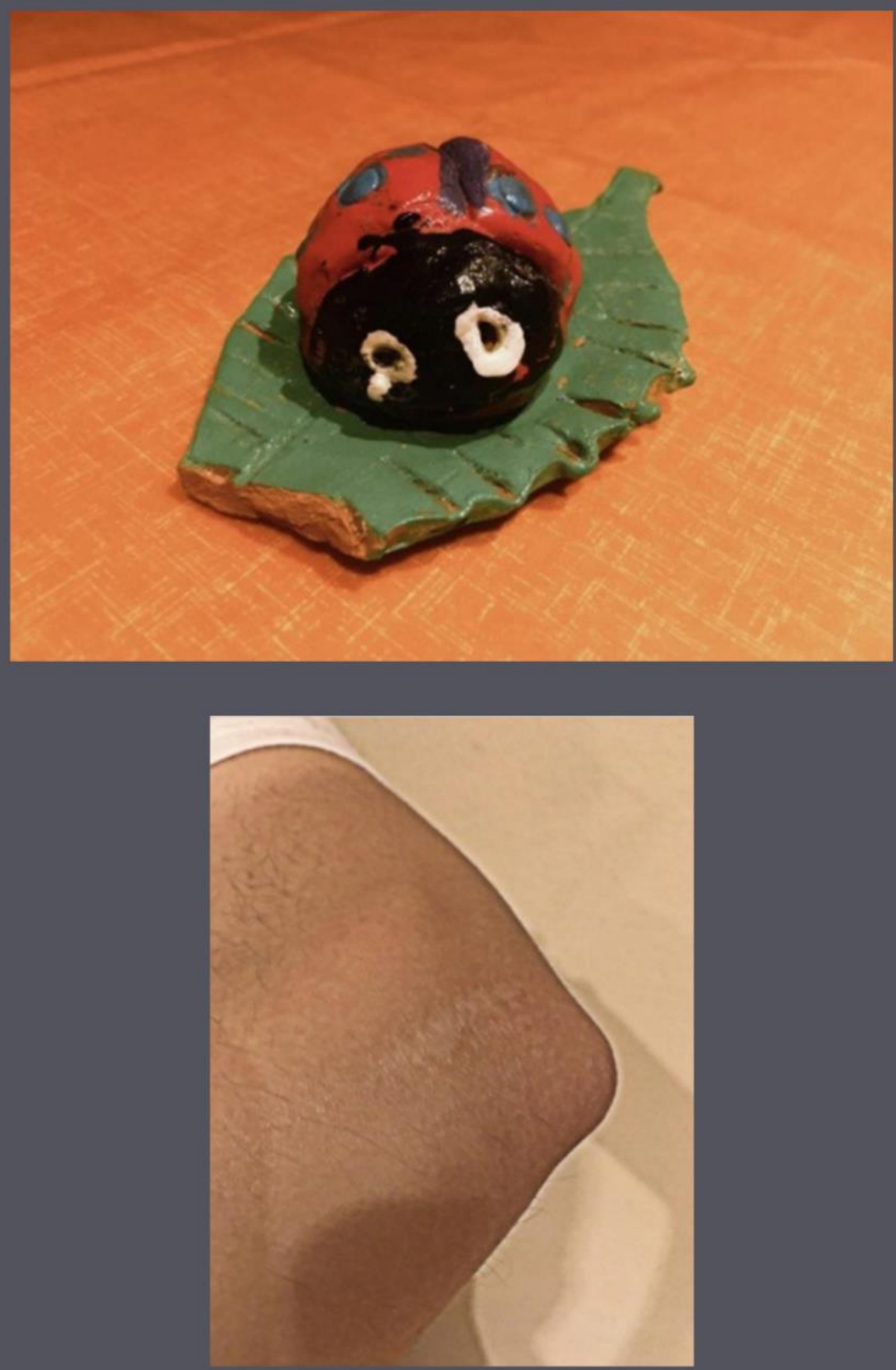


\section{TODAS LAS COSAS SON MUDABLES POR ANA TERESA PINA CLEMENTE}
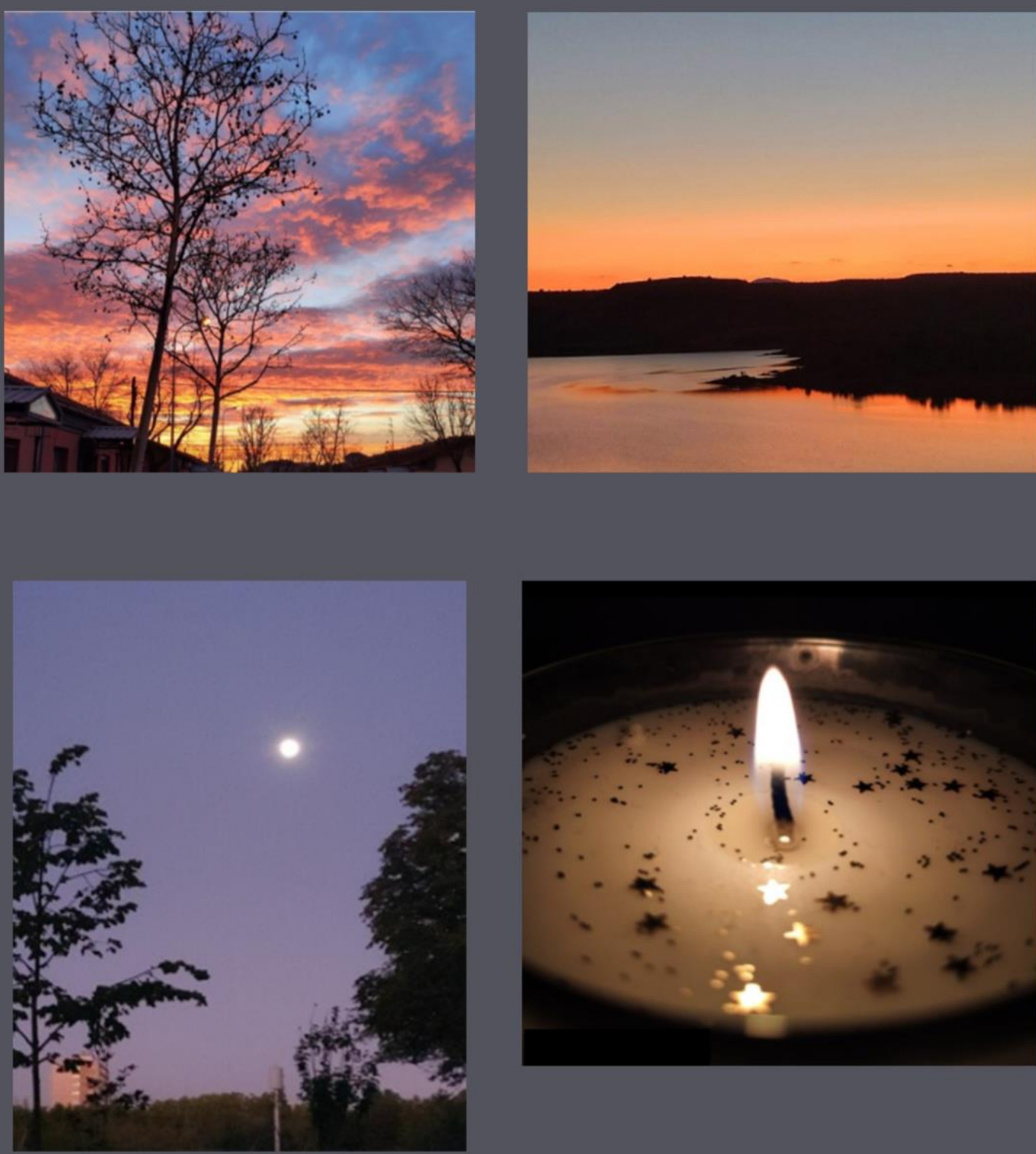


\section{APRECIACIÓN ESTÉTICA DE LA EVANESCENCIA DE LA VIDA POR BELÉN MACDONALD DOMÍNGUEZ}
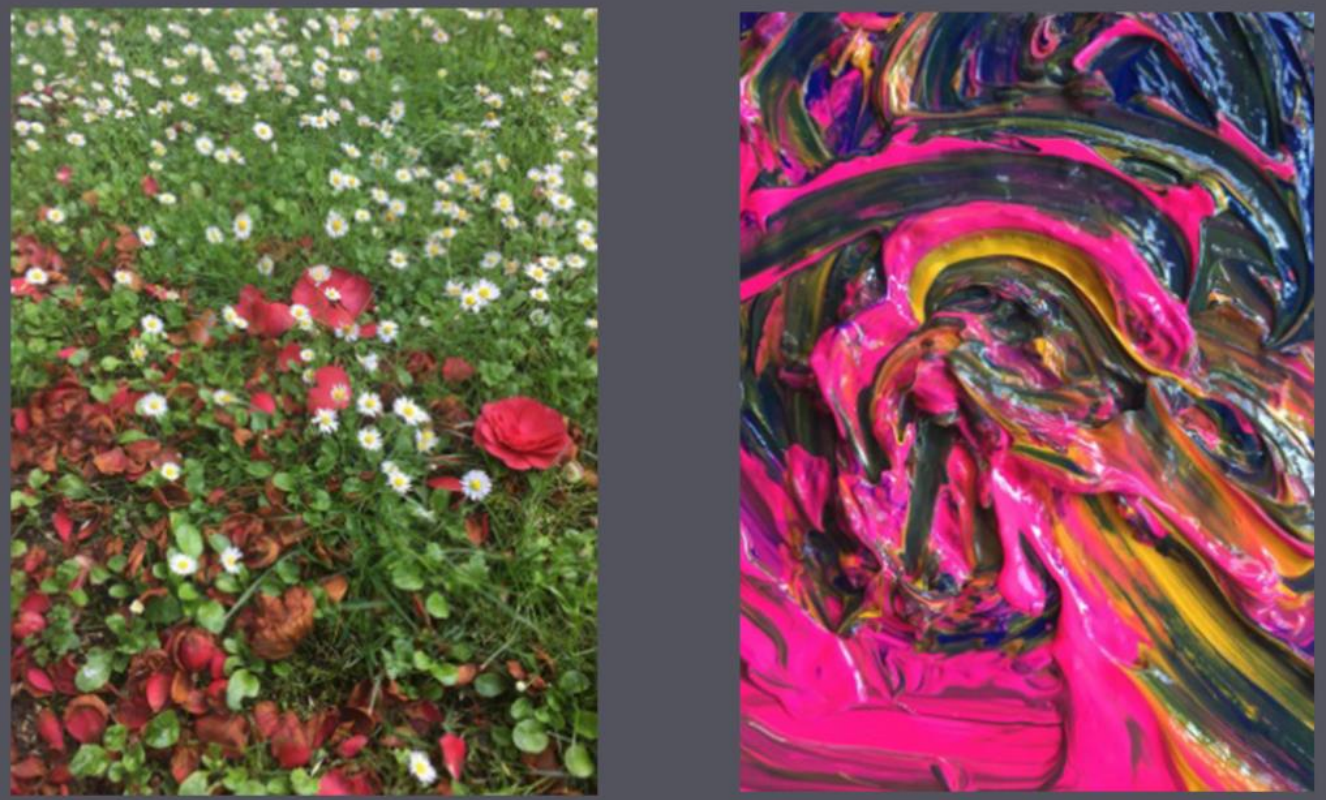


\section{Tercio Creciente}

DOI: https://dx.doi.org/10.17561/rtc.extra4.5745 Investigación
Revista de Estudios en Sociedad,

Artes y Gestión Cultural

ISSN: 2340-9096

Lugares y No Lugares para la creación Diciembre 2020
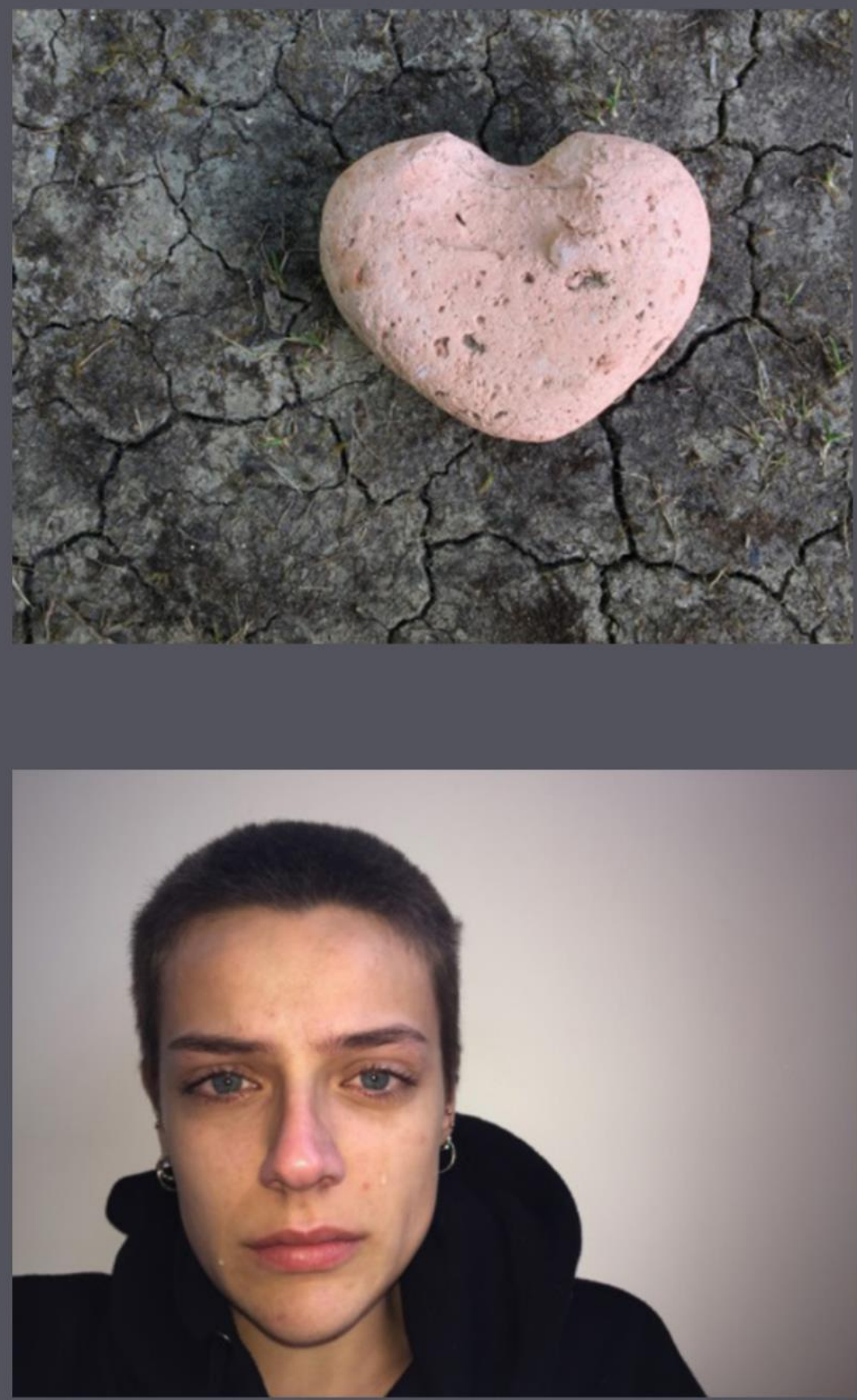


\section{Aprender a mirar}

El fotoensayo muestra imágenes de creación colaborativa de una experiencia artístico pedagógica en el período de confinamiento marzo y abril de 2020.

La experiencia consta de dos partes:

1ạ Taller o laboratorio visual fotográfico partiendo del concepto japonés Wabi-Sabi como detonante de la percepción visual.

2a Parte conceptual en la que se conoce el proyecto creativo del artista contemporáneo Jonathas Andrade a partir del trabajo pedagógico de su madre, maestra de una escuela pública, con la propuesta del diccionario para la alfabetización del pedagogo brasileño Paulo Freire.

Los objetivos coinciden con los generales de la Ley de Educación Infantil y contribuyen desarrollar las siguientes capacidades en la formación de profesorado con el fin de trasladarla a sus futuras aulas:

-Mirar, observar y explorar el entorno personal, familiar, natural, social y cultural.

-Desarrollar la sensibilidad propia, respetar la ajena y las capacidades afectivas.

-Conocer el propio cuerpo, el de otras personas y aprender a respetar las diferencias.

-Entrenar la creatividad y la imaginación.

-Conocer y practicar la fotografía como técnica básica de expresión visual.

-Leer, interpretar y producir imágenes

-Conocer manifestaciones culturales de otros lugares para emplearlas en la expresión propia y poner en valor las de los demás.

El reto era afrontar el confinamiento desde la experiencia. El desarrollo del proyecto consistió en investigar con imágenes partiendo del concepto de Wabi-Sabi para artistas, diseñadores, poetas y filósofos de Leonard Koren (2015), "hay que aflojar el paso, ser paciente y mirar muy de cerca", "cuanto más cerca están las cosas de la no existencia, más exquisitas y evocadoras resultan". La intención es, a través del proyecto creativo y artístico, conectar con la espiritualidad, esencia del ser humano. Poner lo importante en primer plano. 
Es un acercamiento a la belleza de lo imperfecto, lo incompleto, lo cambiante, poner de manifiesto el valor de aquello modesto y humilde. No es lo mismo "ver", que es una experiencia sensorial que "mirar", que implica atención en lo que se ve y, "observar" que requiere un proceso activo y voluntario con un fin determinado. El acto de fotografiar transita las tres, como dice Barthes (1994) "separa la atención (mirar) de la percepción (ver), que sólo muestra la primera, a pesar de ser imposible sin la segunda".

El resultado visual muestra el cumplimiento de los objetivos con fotografías como: del hueco en el polvo, mi cicatriz, autorretrato llorando, del ojo del gato de la señora que ya no está, de grietas, desconchones, de lo roto, lo viejo, lo natural, lo feo, lo perecedero, lo cotidiano, lo inmanente ... en respuesta a las preguntas de partida: ¿Se puede enseñar a mirar?, ¿Cómo se aprende a mirar?, ¿En otras culturas se mira de la misma forma?, ¿Cómo se mira en la infancia?, ¿Qué y cómo se aprende? En la experiencia compartida destaca el aprendizaje activo, el valor del error, de la sensibilidad, la belleza, la aceptación de lo imperfecto, el camino como meta en la construcción del aprendizaje y de la vida para la felicidad. Sólo se enseña lo que se es. Sólo se aprende lo que se vive.

\section{Referencias}

Koren, L. (2018) Wabi-Sabi para Artistas, Diseñadores, Poetas y Filósofos. Sd. Edicions

Barthes, R. (1994) La Cámara Lúcida. Nota sobre la fotografía. Ediciones Paidós 